\title{
RCS celebrates milestone on cutting-edge redevelopment
}

The Grade II ${ }^{\star}$ listed Royal College of Surgeons (RCS) headquarters has celebrated a major landmark in its redevelopment, with a topping out ceremony in Lincoln's Inn Fields, London.

Professor Derek Alderson, President of the RCS (pictured, left), was joined by Sir James Wates (pictured, right), chairman of Wates Group, whose construction arm is carrying out the heritage project, to mark the occasion of reaching the highest point of the build.

The RCS began as the Company of BarberSurgeons, established in 1540, and has been based at Lincoln's Inn Fields since 1796. The historic home of advanced surgical education in the capital is being refurbished to enable it to continue providing the best learning, examination and research resources for the nation's surgeons, while retaining elements of its illustrious history.

In 2019, the number of people waiting for operations across the NHS rose to 4.4 million, increasing the urgency of training more surgeons to cope with demand. With the introduction of new robotic, AI and VR

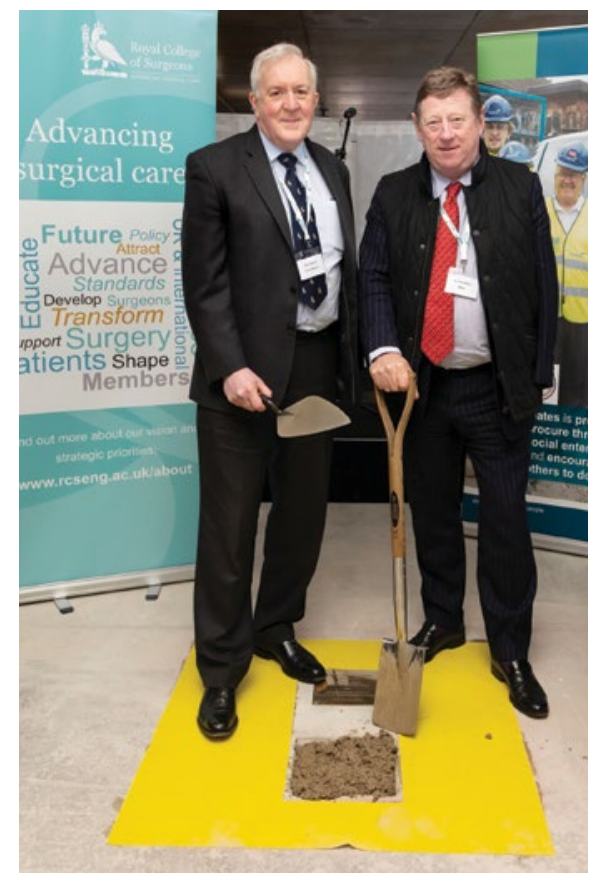

technology in surgery, the shape of surgical

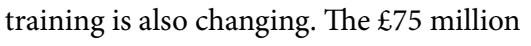
redevelopment of the RCS will provide a modern learning facility that will play an integral role in training the next generation of surgical practitioners.

Upon completion, the Royal College of Surgeons will have an environmentally friendly building, incorporating a highly insulated, air-tight envelope to ensure thermal and energy efficiency; photovoltaic panels on the roof providing a sustainable energy source; and space for $120+$ cyclists to store bikes and shower, encouraging greener travel in the capital.

Speaking at the ceremony, Professor Alderson said: 'This marks an important milestone in transforming our treasured home and the world-famous Hunterian Museum. We will create a modern, state-ofthe-art headquarters for training the next generation of surgeons, and to continue our long history of supporting the exchange of learning and ideas on the future of surgery. The building has been designed to retain our rich surgical heritage, while embracing the cutting-edge future of modern surgery'. 